\title{
PREVENTIVE MEASURES OF OVARIAN HYPERSTIMULATION SYNDROME
}

\author{
Aboubakr M. Elnashar, MD \\ Department of Gynecology and Obstetrics. Benha University Hospital, Egypt
}

\section{ABSTRACT}

Objective : To revicw the up-to-date randomized controlled trials (RCT) \& meta-analyses concerning prevention of ovarian hyperstimulation syndrome (OHSS).

Designs : An electronic scarch of the Cochrane library, Pub Med for RCT \& meta-analyses concerning OHSS from 1990 to 2005 .

Results : Six Cochrane systematic reviews, 4 meta-analyses \& 28 RCT were reviewed as regarding choice of the treatment regimen, preventive measures on the day of human chorionic gonadotrpin (HCG), on the day of oocyte retrieval, at the time of embryo transfer \& during the luteal phase.

Conclusions : 1. Laparoscopic ovarian drilling \& use of urinary follicle stimulating homone (uFSH) rather than human menopausal gonadotropin (HMG) in stimulation cycles without concomitant use of a GnRh-a are associated with reduction of OHSS in polycystic ovary syndrome (PCOS). 2. Significant reduction in incidence of OHSS is observed with low dose step up FSH protocol. 3. Recombinant luteinising homone (rLH) results in a highly significant reduction in OHSS compared to urinary luteinising hormone (uHCG). 4. Use of gonadotropin releasing hormone agonist (GnRHa) instead of HCG in antagonist protocol is associated with reduction of OHSS. 5. There is insufficient evidence to determine if coasting is an effective strategy for preventing OHSS 6. Administration of human albumin is not effective in reduction of severe OHSS. 7. Given the increased risk of OHSS associated with HCG, intramuscular (IM) progesterone is favored for luteal phase supplementation.

Keywords : Ovarian hyperstimulation syndrome, controlled ovarian hyperstimulation, assisted reproductive technologies.

\section{INTRODUCTION}

Ovarian hyperstimulation syndrome (OHSS) is an iatrogenic complication of assisted reproductive technology; so prevention is the most important tool for patient safety.

There are divergent opinions regarding the effective strategies for prevention of OHSS. Different strategies for prevention of OHSS are known. Before starting controlled ovarian hyperstimulation $(\mathrm{COH})$, patients at high risk for OHSS should be identified \& the appropriate treatment regimen is selected. Risk factors developing during $\mathrm{COH}$ should be detected \& preventive measures are taken on the day of $\mathrm{HCG}$, on the day of oocyte retrieval, at the time of embryo transfer \& during the luteal phase.

\section{A. Choice of the treatment regimen}

\section{In PCOS:}

a. Ketoconazole does not prevent OHSS in patients with PCOS who are undergoing ovarian stimulation. It may reduce the rate of folliculogenesis and steroidogenesis (I). 
b. Laparoscopic ovarian electrocautery is a useful treatment for women who have previously had an IVF cycle cancelled due to risk of OHSS or who have suffered OHSS in a previous cycle ${ }^{(2)}$.

c. HMG Vs uFSH : There is a reduction in the incidence of OHSS with uFSH compared to HMG in stimulation cycles without concomitant use of a GnRh-a (3).

d. HMG/FSH alone Vs GnRHa plus FSH/HMG: An increased risk of OHSS associated with GnRHa use (4).

\section{Method:}

a. Antagonist Vs agonist: No statistically significant reduction in incidence of severe OHSS $^{(5)}$.

b. Cetrorelix Vs ganirelex: Cetrorelix but not ganirelex reduce the incidence of OHSS ${ }^{(6)}$.

\section{Protocol}

Ultrashort Vs long Protocol: Lower rate of OHSS in ultrashort protocol than in the long one ${ }^{(7)}$.

\section{Gonadotrophin:}

a. Dose

i. Gonal F: 150 IU Vs 225 IU: Incidence is higher with $225 \mathrm{IU}^{(8)}$.

ii. Puregon: 100 Vs 200 IU: The incidence of OHSS is higher in the high dose group $(9-11)$.

\section{b. Regimen}

i. Low dose step up FSH Vs conventional FSH protocol: Significant reduction in incidence of OHSS was observed in the low dose group ${ }^{(12)}$.

ii. Chronic low dose Vs conventional rFSH: No difference in OHSS (13). iii. Conventional Vs personalized protocol: A personalized regimen based on body mass index (BMI) \& waist/hip ratio is not associated with any significant increase in severe OHSS ${ }^{(14)}$.

c. Type:

i. Highly purified (HP)- HMG Vs rFSH: The incidence of OHSS was similar in both treatment groups $(15,16)$.

ii. HMG Vs rFSH: No difference (17).

iii. rFSH Vs uFSH: No difference ${ }^{(18,19)}$.

iv. Gonal F Vs puregon: The incidence of OHSS was similar ${ }^{(20)}$.

d. Monitoring:

Ultrasound versus ultrasound and hormonal levels: Pregnancy and OHSS rates were similar $(34.3 \%$ vs. $31.4 \%$ and $4.9 \%$ vs. $4.1 \%$, respectively) (21). The addition of estradiol (E2)/follicle criteria to ultrasound monitoring of IVF cycles in normal responders seldom changes the timing of $\mathrm{HCG}$, and does not increase pregnancy rates or the risk of OHSS.

\section{B. On the day of HCG}

1. Rec LH Vs uHCG: Rec LH is effective in inducing final follicular maturation \& is comparable with uHCG. Rec LH results in a highly significant reduction in OHSS compared with uHCG. ${ }^{(22,23)}$. The dose of rLH giving the highest efficacy to safety ratio was between 15.000 \& $30.000 \mathrm{IU}$.

2. Coasting Vs early unilateral follicular aspiration: There was no difference in the incidence of moderate \& severe OHSS \& in the clinical pregnancy rate between the groups ${ }^{(24)}$. Compared with elective unilateral follicular aspiration (elective aspiration of excess ovarian follicles), 
there was no convincing benefits associated with the use of coasting. There is a lack of RCT for comparing coasting with no coasting or other interventions such as embryo freezing or intravenous albumin infusion for prevention of OHSS. There is insufficient evidence to determine if coasting is an effective strategy for preventing OHSS.

3. Unilateral ovarian early follicular aspiration prior to HCG administration does not reduce the occurrence of severe OHSS in women at risk $(25,26)$.

4. $\mathrm{HCG} V \mathrm{~s}$ agonist in triggering final oocyte maturation in antagonist protocol: With $\mathrm{GnRH}$ agonist instead of HCG in IVF cycles dramatically decreases luteal levels of inhibins reflecting significant inhibition of the corpous luteum function (27). This may explain the mechanism of OHSS prevention by the use of GnRH agonist.

\section{On the day of oocyte retrieval}

1. IV albumin: Meta-analysis demonstrated significant reduction in severe OHSS on administration of human albumin at the time of oocyte retrieval in high risk cases ${ }^{(28)}$. Eightteen women at risk needed to be treated with albumin infusion in order to prevent a single case of severe OHSS. This needs to be taken into account in the context of clinical decision making. On the other hand, Ben-Chetrit et al, ${ }^{(29)}$ reported that albumin has no positive effect on OHSS or conception rates, while its use carries the risk of undesirable side effects, including exacerbation of ascites in OHSS, nausea, vomiting, febrile reaction, allergic reaction, anaphylactic shock and risk of virus transmission. They suggested that this form of treatment should not be included in the prevention of OHSS. Albumin infusion on the day of oocyte retrieval is not a useful means of preventing the development of moderate-severe $\operatorname{OHSS}^{(30)}$.

2. IV hydroxyethyl starch: Administration of 6\% hydroxyethyl starch prevents the development of moderate-severe OHSS in high risk patients (31).

3. Albumin Vs starch: Both significantly reduced the incidence of OHSS, but starch is a cheaper \& safer alternative to human albumin ${ }^{(32)}$.

4. Albumin Vs high dose of progesterone: IM progesterone (200 $\mathrm{mg} /$ day) \& $100 \mathrm{ml}$ of $20 \% \mathrm{IV}$ albumin are effective in preventing OHSS ${ }^{(33)}$.

5. Glucocorticoids: Administration of glucocorticoids (Hydrocortisone $100 \mathrm{mg}$ IV, immediately after oncyte retrieval followed by prednisolone $10 \mathrm{mg}$ two times a day for 3 days \& $10 \mathrm{mg} / \mathrm{d}$ for 2 days) to high risk patients did not reduce the rate of OHSS after ovarian stimulation for IVF (34)

\section{At the time of embryo transfer}

1. Transferring a single zona-free day 5 embryo (blstocyst) \& freezing of the supernumerary embryos offers the patient at risk of OHSS an optimal chance for a singleton pregnancy, while avoiding the serious maternal complications of OHSS (35).

2. Elective cryopreservation of all embryos: $A$ systematic review has found that there is insufficient evidence to support routine cryopreservation in cases with a high risk of OHSS, for elective cryopreservation versus intravenous albumin or elective cryopreservation versus fresh embryo transfer ${ }^{(36)}$.

\section{E. Luteal phase support}

1. HCG Vs progesterone. A recent meta-analysis reported no fertility difference when comparing IM progesterone with $\mathrm{HCG}{ }^{(37)}$. Given the increased 
risk of OHSS associated with HCG, IM progesterone is favored for luteal phase supplementation.

2. Progesterone (P) alone Vs progesterone combined with HCG: More cases of OHSS were found in the $\mathrm{P} / \mathrm{HCG}$ group. Vaginal $\mathrm{P}$ alone provides sufficient luteal support in GnRHa/HMG induced IVF cycles ${ }^{(48)}$.

\section{REFERENCES}

1- Parsanezhad ME, Alborzi S, Pakniat M, Schmidt EH.

A double-blind, randomized, placebo-controlled study to assess the efficacy of ketoconazole for reducing the risk of ovarian hyperstimulation syndrome. Fertil Steril 2003 Nov; 80(5): 1151-5.

2- Rimington MR, Walker SM, RW. The use of laparoscopic ovarian electrocautery in preventing cancellation of in-vitro fertilization treatment cycles due to risk of ovarian hyperstimulation syndrome in women with polycystic ovaries. Hum Reprod 1997 Jul; 12(7): 1443-7.

3- Nugent D, Vandekerckhove P, Hughes E, Arnot M, Liford R. gonadotrophin therapy for ovulation induction in subfertilityassociated with polycystic ovary syndrome. The Cochrane Library, Issue 1, 2000. Oxfor: Update Software.

4- Hughes EG, Fedorkow DM, Daya S, Sagle MA, Van de Koppel P, Collins JA. The routine use of gonadotropin-releasing hormone agonists prior to in vitro fertilization and gamete intrafallopian transfer: a meta-analysis of randomized controlled trials. Fertil Steril 1992 Nov; 58(5): 888-96.

5- Al-Inany $\mathrm{H}$, Aboulghar $\mathrm{M}$. GnRH antagonist in assisted reproduction: a Cochrane review. Hum Reprod 2002 Apr; 17(4): 874-85.

6- Ludwig M, Felberbaum RE, Devroey P, Albano C, Riethmuller-Winzen $H$, Schuler A, Engel $W$, Diedrich K. Significant reduction of the incidence of ovarian hyperstimulation syndrome (OHSS) by using the LHRH antagonist Cetrorelix (Cetrotide) in controlled ovarian stimulation for assisted reproduction. Arch Gynecol Obstet 2000 Jul; 264(1): 29-32.

7- Strohmer H, Chatwani S, Wieser F, Danninger B, Obruca A, Feichtinger W. Prospective randomized study of an ultrashort gonadotrophin-releasing hormone agonist versus a modified suppression protocol for ovarian stimulation in intracytoplasmic sperm injection cycles. Hum Reprod 1997 Jul; 12(7): 1403-8.

8- Ykong PY, Brett S, Baird DT, Thong KJ. A prospective randomized clinical trial comparing 150 IU and 225 IU of recombinatnt follicle-stimulating hormone (Gonal-F*) in a fixed-dose regimen for controlled ovarian stimulation in vitro fertilization treatment. Fertil Steril 2003 Feb; 78(2): 308-15.

9- Out HJ, Lindenberg S, Mikkelsen Al, Eldar-Geva T, Healy DL, Leader A, Rodriguez-Escudero FJ, Garcia-Velasco JA, Pellicer A. A prospective, randomized, double-blind clinical trial to study the efficacy and efficiency of a fixed dose of recombinant follicle stimulating hormone (Puregon) in women undergoing ovarian stimulation. Hum Reprod. 1999 MAr; 14(3): 622-7.

10- Ng EY, Ycung WS, Ho PC. Comparison of two dosages of recombinant human follicle-stimulating hormone in Chinese women undergoing controlled ovarian stimulation: prospective randomized double-blind study. Hong Kong Med J 2000 Dec; 6 (4): $368-374$.

II- Out HJ, David I, Ron-El R, Friedler S, Shalev E, Geslevich J, Dor J, Shulman A, Ben-Rafael Z. Fisch B, Dirnfeld M. A randomized, double-blind clinical trial using fixed daily doses of 100 or 200 IU of recombinant FSH in ICSI cycles. Hum Reprod 2001 Jun; 16(6): 1104-1109.

12- Sengoku J, Tumate J, Takaoka Y, Horikawa M, Goishi K, Komori H, Okada R, Tsuchiya K, Ishikawa $M$. The clinical efficacy of low-dose step-up follicle stimulating hormone administration for treatment of unexplained infertility. Hum Reprod 1999 Feb; 14(2): 349-353.

13- Hedon B, Hugues JN, Emperaire JC, Chabaud JJ, Barbereau D, Boujenah A, Howles CM, Truong F. A comparative prospective study of a chronic low 
dose versus a conventional ovulation stimulation regimen using recombinant human follicle stimulating hormone in anovulatory infertile women. Hum Reprod 1998 Oct; 13(10): 2688-2692.

14- Pellicano M, Zullo F, Dl Cario C, Mastrantonio P, Nappi C. Controlled ovarian hyperstimulation: comparison between u-hFSH conventional protocol and a personalized approach. Int J Fertil Womens Med 1997 Jul-Aug; 42(4): 264-267.

15- Franco JG Jr, Baruffi RL, Coelho J, Mauri Al, Petersen CG, Garbellini E. A prospective and randomized study of ovarian stimulation for ICSI with recombinant FSH versus highly purified urinary FSH. Gynecol Endocrinol 2000 Feb; 14(1): 5-10.

16- European and Israeli Study Group on Highly Ourificd Menotropin versus Recombinant Follicle-Stimulating Hormone. Efficacy and safety of highly purified menotropin versus recombinant follicle-stimulating hormone in vitro fertilization/intracytoplasmic sperm injection cycles: a randomized, comparative trial Fertil Steril 2002 Sep; $78(3): 520-528$.

17- Van Wely M, Westergaard LG, Bossuyt PM, Van der Veen F. Human menopausal gonadotropin versus recombinant follicle stimulation hormone for ovarian stimulation in assisted reproductive cycles. Cochrane Database Syst Rev 2003; (1): CD003973. Review.

18- Yarali H, Bukulmez $O$, Gurgan $T$. Urinary follicle-stimulating hormone (FSH) versus rccombinant FSH in clomiphene citrate-resistant, normogonadotropic, chronic anovulation: a prospective randomized study. Fertil Steril 1999 Aug; 72(2): 276-281.

19- Daya $S$. Updated meta-analysis of recombinant follicle-stimulating hormone (FSH) versus urinary FSH for ovarian stimulation $\mathrm{n}$ assisted reproduction. Fertil Steril 2002 Apr; 77(4): 711-714.

20- Tulppala M, Aho M, Tuuri T, Vilska S, Foudila T, Hakala-Ala-Pietila T, Moilanene J, Buczow T, Kaukoranta S, Soderstrom-Anttila V, Siegberg R, Suikkari AM, Hovatta O. Comparison of two recombinant follicle-stimulating hormone preparations in in-vitro fertilization: a randomized clinical study. Hum Reprod 1999 Nov; 14(11): 2709-2715.

21- Lass A; UK Timing of hCG Group. Monitoring of in vitro fertilization-embryo transter cycles by ultrasound versus by ultrasound and hormonal levels: a prospective, multicenter, randomized study. Fertil Steril 2003 Jul: 80(1): 80-85.

22- Furopean Recombinant LH Study Group. Human recombinant luteinizing hormone is as effective as but safer than, urinary human chorionic gonadotropin in inducing final follicular maturation and ovulation in in vitro fertilization procedures: results of a multicenter double-blind study. J Clin Endocrinol Metab 2001 Jun; 86(6): 2607-2618.

23- Weigert M, Krischker U, Pohl M, Poschalko G, Kindermann $C$, Feichtinger $W$. comparison of stimulation with clomiphene citrate in combination with recombinant follicle-stimulating hormone and rccombinant luteinizing hormone to stimulation with a gonadotropin-releasing hormone agonist protocol: a prospective, randomized study Fertil Steril 2002 Jul; $78(1): 34-39$.

24- D'Angelo A, Amso N. "Coasting" (withholding gonadotrophins) for preventing ovarian hyperstimulation syndrome. The Cochrane Library, Issue 4, 2003. Chichester, UK: John Wiley \& Sons, Ltd.

25- Egbase PE, Makhsecd M, Al Sharhan M, grudzinskas JG. Timed unilateral ovarian follicular aspiration priol to administration of human chorionic gonadotrophin for the prevention of sevcre ovarian hyperstimulation syndrome in in-vitro fertilizaton: a prospective randomized study. Hum Reprod 1997 Dec; 12(12): 2603-2606.

26- De Geyter C, De Geyler M, Castro E, Bals-Pratsch M, Nicschlag E, Schneider HP. Experience with transvaginal ultrasound-guided aspiration of supernumerary follicles for the prevention of multiple pregnancies after ovulation induction and intrautcrine insemination. Fertil Steril $1996 \mathrm{Jn} ; 65$ (6): $1163-1168$.

27- Nevo O, Eldar-Geva T, Kil S, Itskovitz-Eldor J. Lower levels of inhibin $A$ and proalphac during the 
luteal phase after triggering oocyte maturation with a gonadotropin-releasing homone agonist versus human chorionic gonadotropin. Fertil Steril 2003 May; 79(5): 1123-1128.

28- Aboulghar M, Evers JH, Al-Inany $\mathrm{H}$. Intravenous albumin for preventing severe ovarian hyperstimulation syndrome. The Cochrane Library, Issue 4, 2003. Chichester, UK: John Wiley \& Sons, Ltd.

29- Ben-Chetrit A, Eldar-Geva T, Gal M, Huerta $M$, Mimon T, Algur N, Djamant YZ, Margalioth EJ, The questionable use of albumin for the prevention of ovarian hyperstimulation syndrome in an IVF programme: a randomized placebo-controlled trial. Hum Reprod 2001; 16(9): 1880-4.

Bellver J, Mo noz E, Ballesteros A, Soares S, Bosch E, Simon C, Pellicer A, Remohi J. Intravenous alburmin does nol prevent moderate-severe ovarian hyperstimulation syndrome in high-risk IVF patients: a randomized controlled study. Hum Reprod 2003; 18, (11): 2283-2288.

30- Konig E, Bussen S, Sutterlin M, Steck T. Prophylactic intravenous hydroxyethyle starch solution prevents moderate-severeovarian hyperstimulation in in-vitro fertilization patients: a prospective, randomized, double-blind and placebo-controlled study. Hum Reprod 1998 Sep; 12(9): 2421-2424.

31- Gokmen O, Ugur M, Ekin M, Keles G, Turan C, Oral $H$. Intravenous albumin versus hydroxyethyl starch for the prevention of ovarian hyperstimulation in an in-vitro fertilization programme: a prospective randomized placebo controlled study. Eur J Obstel Gynecol Reprod Biol
2001 Jun; 96(2): 187-192.

32- Abramov Y, Fatum M, Abrahamov D, Schenker JG. Hydroxyethylstarch versus human albumin for the treatment of severe ovarian hyperstimulation syndrome: a preliminary report. Fertil Steril 2001 Jun; 75(6): 1228-1230.

33- Costabile L, Unfer V, Manna C, Gerli S, Rossetti D, Dl Renzo GC. Use of intramuscular progesterone versus intravenous albumin for the prevention of ovarian hyperstimulation syndrome. Gynecol Obstet Invest $2000 ; 50(3) ; 182-5$.

34- Tan SL, Balen A, el Hussein E, Campbeli S, Jacobs HS. The adminisration of glucocorticoids for prevention of ovarian hyperstimulation syndrome in in-vitro fertilization: a prospective randomized study. Fertil Steril 1992; 58(20): 378-383.

35- Kinget K, Nijs M, Cox AM, Janssen M, Jacobs P, Bosmans E, Ombelet W. A novel approach for patients at risk for ovarian hyperstimulation syndrome: clective transfer of a single zona-free blastocyst on day 5. Reprod Biomed Online 2002 Jan-Feb; 4(1): 5]-55.

36- D'angelo A, Amso N. Embryo freezing for preventing ovarian hyperstimulation syndrome. The Cochrane Database Syst Rev 2002; (2): CD002806.

37- Pritts EA, Atwood AK. Luteal phase support in infertility treatment: a meta-analysis of the randomized trials. Hum Reprod 2002 Sep; 17(9): 2287-2299.

38- Mochtar MH, Hogerzeil HV, Mol BW, Progesterone alone versus progesterone combined with $\mathrm{HCG}$ as luteal support in $\mathrm{GnRHa} / \mathrm{HMG}$ induced IVF cycles: a randomized clinical trial. Hum Reprod 1996 Aug; 11(8): 1602-1605. 